EMBRYARIDDLE
Aeronautical University

SCHOLARLY COMMONS

\section{International Journal of Aviation,} Aeronautics, and Aerospace

\title{
Evaluating the Effect of Turbulence on Aircraft During Landing and Take-Off Phases
}

\author{
Anthony O' Connor \\ Dublin Institute of Technology, anthony260610@gmail.com \\ Derek Kearney \\ Dublin Institute of Technology, derek.kearney@dit.ie
}

Follow this and additional works at: https://commons.erau.edu/ijaaa

Part of the Aerospace Engineering Commons, and the Aviation Safety and Security Commons

\section{Scholarly Commons Citation}

O' Connor, A., \& Kearney, D. (2018). Evaluating the Effect of Turbulence on Aircraft During Landing and Take-Off Phases. International Journal of Aviation, Aeronautics, and Aerospace, 5(4). https://doi.org/ 10.15394/ijaaa.2018.1284

This Position Paper is brought to you for free and open access by the Journals at Scholarly Commons. It has been accepted for inclusion in International Journal of Aviation, Aeronautics, and Aerospace by an authorized administrator of Scholarly Commons. For more information, please contact commons@erau.edu. 


\section{Evaluating the Effect of Turbulence on Aircraft During Landing and Take-Off}

Phases

\section{Cover Page Footnote}

Additional references inserted with figures as indicated by David S Cross 


\section{INTRODUCTION}

The aviation industry supports $\$ 2.7$ trillion of the world gross domestic product which accounts for $3.5 \%$ of the world GDP. This is more than double that of the automotive industry and greater that the chemical and automotive industries combined. Commercial aviation is second only to the global financial services industry. Just to put this into perspective, if the commercial aviation industry were a country, its GDP would rank 21 st in the world. The aviation industry carries over 3 billion passengers a year.

Low level Wind shear can affect aircraft performance and has potentially adverse effects on flight safety during landing and take-off phases. Providing immediate and accurate data relating to all prevailing wind conditions including low level wind shear on the runway is crucial for approaching aircraft. Providing the pilot with a complete and comprehensive analysis of wind conditions will facilitate the pilot's decision to land or to go-around. The problem for the commercial aviation industry can be broken into two areas. The first area is human safety which can result in the loss of life or injury to passengers and crew from a plane crash or plane landing related accident. The second area is the monetary cost associated with resulting loss or damage to an aircraft, knock on delays to other aircraft, addition fuel used in the go-around procedure, baggage handling delays and the additional cost of man power resources.

The problem caused by low level wind shear on aircraft is well documented and recognized in literature - the aviation industry concluded that the majority of accidents that occurred over the past 10 years have occurred during the approach, landing and go-around flight phases. At the Go-around safety forum in Brussels in 2013, it was concluded that due to rapid changing weather and runway conditions, a pilot does not always have the latest information on which to make a landing or go-around decision (EUROCONTROL, 2013). Air accident reports have stated that between 2000 and 2012 there were 10 fatal accidents attributed to flight go-arounds in which 614 people died. Six go-around safety issues were identified with $57 \%$ of risk bearing go-arounds being attributed to the crew failing to initiate the go-around procedure. At the Brussels forum it was established that out of 44 risk bearing goaround decisions taken by crew, $45 \%$ of the go-arounds were because of an unstabilized approach on landing. The weather conditions were responsible for $34.7 \%$ of all go-around procedures. A further conclusion of the Brussels forum was that improved information should be provided to crews in relation to tailwinds, wind shear and wind variations. In several air accident reports some involving fatalities, it has been concluded that the lack of real time adverse wind shear information can be attributed to the cause of the accident. A report in 2002 by the Australian Transport Safety Bureau (ATSB) into an accident caused by a microburst involving 
a Boeing 737-400 (ATSB, 2002) recommended that "the Bureau of Meteorology expedite the research and development program to examine wind shifts and wind shear, with the objective to improve the detection and forecasting of wind shifts and the detection of wind shear in the vicinity of high risk airport terminal areas" (para. 4.1.2.4) and that the Civil Aviation Safety Authority place greater emphasis on the effect of wind shear. The report went on to state that aircraft in the go-around phases are particularly vulnerable to the effects of microburst wind shear which can place the aircraft in a potentially high-risk situation.

A solution to the problem of forecasting low level wind shear and turbulence for the approach, landing and go-around flight phases for aircraft could be addressed by incorporating the wind urchin as part of the Low Level Wind Shear Alerting System (LLWAS) in all airports.

This requires a change of approach and thinking on the characteristics of wind measurement when quantifying and analyzing wind shear, turbulence and microburst for the approach, landing and go-around phases for aircraft. The basic wind instruments such as the cup and vein developed in the 19th century are still broadly similar in design to the ones in use today. These instruments are constructed and limited by their design to only measure wind as a two-dimensional entity. The data obtained from these instruments is used to provide the information to the air traffic controller who then relays this to the aircraft crew concerning the presence of low level wind shear. Equipped with this limited data and analysis of the prevailing wind shear conditions, the crew must decide on what course of action to take when coming in to land. Wind shear can be summarized as a change in wind speed and or direction in space including updrafts and downdrafts. Wind blows freely in three-dimensional space but is only measured in two dimensions. It must be noted that wind shear is a vector and hence the speed and direction of the two winds must be factored into the equation. Because of the complexity of wind shear, it cannot be calculated by simple scalar calculation of wind speeds. Current methods of wind shear calculations involve data from an aircraft on descent and recording data from different anemometer spaced at different levels along a runway of mast. The limitation in this approach is that the calculation of wind shear from two winds separated by a distance gives the overall wind shear between those two points. The information does not indicate if the rate of shear is linear or not or where most of the shear occurs between the points sampled. It is wholly inadequate and does not give the maximum shear (International Civil Aviation Organization [ICAO], 2005).

This would indicate that traditional meteorological instrumentation used in the aviation industry are not adequately providing all the necessary data required by the air traffic controllers and flight crew with the information that is critically 
on approach and landing, leading to greater safety of passengers and crew.

\section{DISRUPTION TO AIRCRAFT}

Low level wind shear can affect aircraft performance and has potentially adverse effects on flight safety during landing and take-off phases. It cannot be underestimated how serious the effect of low level wind shear can be on an approaching aircraft. The disruption cause by wind shear and low level turbulence can range from severe, resulting in an aircraft accident and fatalities to minor resulting in delays at airports and additional resulting monetary costs. Wind shear can occur at any level but low level wind shear can cause problems of such magnitude that it can affect the air crew's ability to control the plane during takeoff or on approach to landing (Civil Aviation Authority, 2013). Airline companies, civil aviation authorities and the Flight Safety foundation have produced reports and manuals for Air Traffic controllers and flight crews in stipulated procedures to be followed when a low level wind shear warning has been issued (Flight Safety Foundation, 2009). Increased pilot training in dealing with the problems caused as a result of low level wind shear and turbulence has been adapted by all major airlines (ICAO, 2005). Despite all the advances in wind shear and turbulence warning systems at airports, the conclusion from many reports have stated that the best course of action for a pilot to take is to avoid wind shear completely (Albright, 2015). The concluding summary issued to airlines by the ICAO in their manual on low level wind shear was to avoid wind shear and if in doubt, delay take off and on approach, hold until conditions improve or divert to an alternative airport.

\section{ADVERSE EFFECTS ON FLIGHT SAFETY}

Wind shear can be defined as the sudden change of wind velocity and or direction. In order to understand the effect that wind shear and turbulence can have on an aircraft, it is important to understand the four main forces that act on an aircraft while in flight. The thrust is provided by the engines, the lift is provided by the wings, the third and fourth force acting on the aircraft is the weight of the aircraft and the drag from the aircraft. In non-accelerating flight the thrust has to balance the drag and the lift has to balance the weight. When the forces on the aircraft are in equilibrium there are no resultant forces and in accordance of Newton's first law of motion, this will continue whether the aircraft is climbing, descending or in level flight until the balance is disturbed. In a normal level flight, the thrust has to balance the drag and the lift has to balance the weight. In a flight that is climbing the thrust also has to balance a portion of the weight $(W \sin \gamma)$, hence more thrust is needed that in normal level flight and the thrust is proportional to the angle of climb. The four main forces acting on an aircraft are affected by wind shear. Figure 1 shows the forces acting on an aircraft in flight. 


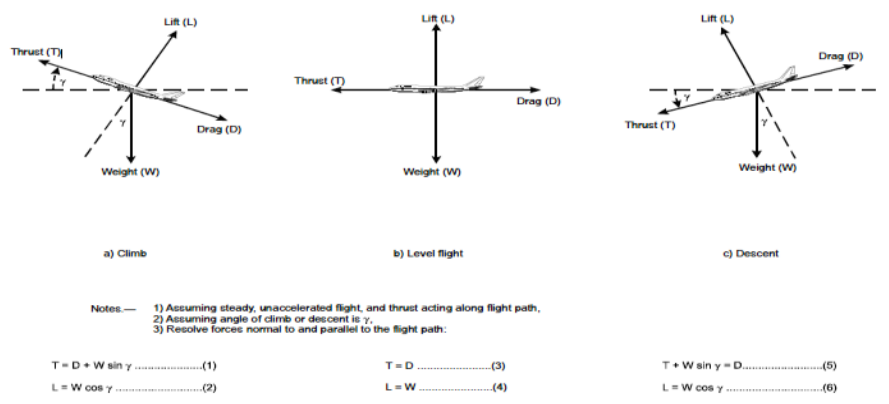

Figure 1. Wind Shear Effect for Aircraft Taking Off (ICAO, 2005)

The thrust $(T)$ of the aircraft is the force produced by the aircraft engines; the weigh $(W)$ is defined as the mass $(m)$ of the aircraft $\mathrm{x}$ acceleration due to gravity $(g)$ where $W=m g$. The lift $(L)$ and $\operatorname{drag}(D)$. From Equations 1 and Equation 2 the angles of climb of the aircraft can be derived.

$$
\begin{array}{ll}
T=D+W \gamma & \text { Eqt: } 1 \\
\gamma=\frac{T-D}{W} & \text { Eqt: } 2 \text { Where }
\end{array}
$$

The Lift $(L)$ and Drag $(D)$ are proportional to the density of the air $(\rho)$, the area of the wing $(S)$ and the square of the velocity of the air passing over the wings. (V) L\&D $\alpha \rho, \mathrm{S} \& \mathrm{~V}^{2}$. The lift and drag coefficients CL and CD are constants of proportionality such that,

$$
\begin{aligned}
& \mathrm{L}=1 / 2 \mathrm{CL}_{\rho} \mathrm{S} \mathrm{V}^{2} \\
& \text { And } \\
& \mathrm{D}=1 / 2 \mathrm{CD} \rho \mathrm{S} \mathrm{V}^{2}
\end{aligned}
$$

These equations demonstrate that the lift and drag depend on the angle of attack on the wing and the square of the airspeed. Wind shear can affect both the angle of attack and the airspeed which in turn can affect lift and drag. This in turn disturbs the equilibrium of the aircraft. Vertical wind shear causes variations of the horizontal component of the wind which can affect the aircraft speed on approach to landing or on take-off. Horizontal variations of the wind can result in an increase or decrease in head and tail wind affecting the landing and take-off of aircraft. Extreme low level wind shear and turbulence can at its worst cause an aircraft to crash resulting in fatalities and injuries to passengers and crew and destruction or damage to an aircraft. At the lower end of the scale, wind shear and turbulence will result in delays to take offs and landings, aborted landings resulting in flight go- 
around manoeuvres or flights being diverted to another airport. Figure 2 illustrates the effect of wind shear on aircraft coming in to land. It can be seen that the speed of the aircraft is increased by the wind resulting in a greater stopping distance being needed to halt the aircraft. Figure 3 illustrates the effect of wind shear on aircraft during taking-off.

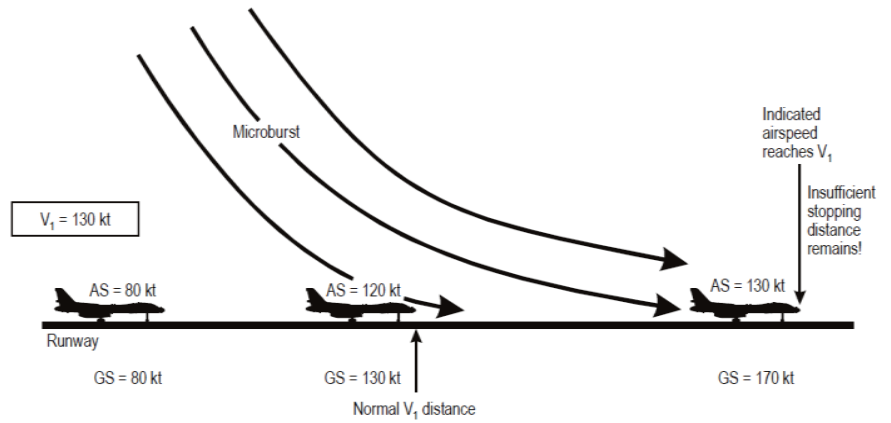

Figure 2. Wind Shear Effect for Approaching Aircraft (ICAO, 2005)

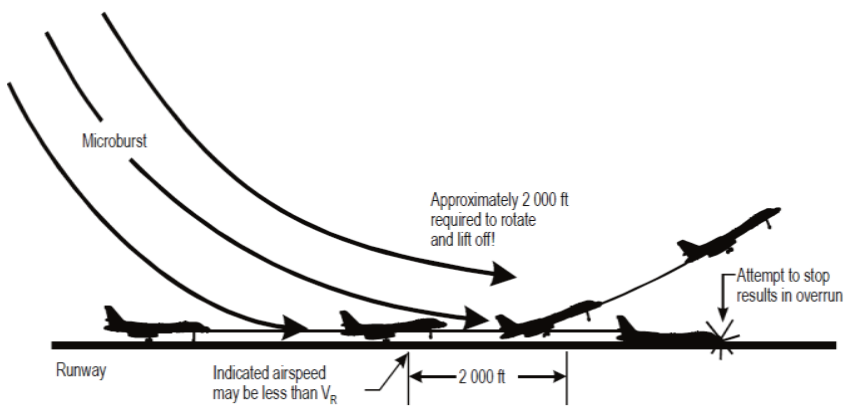

Figure 3. Wind Shear Effect for Aircraft Taking Off (ICAO, 2005)

According to the U.S. Department of Transport records from the National Aviation System (NAS), 33\% of all delayed flights in 2016 were due to weather conditions. The figure for 2017 is over $50 \%$ due to weather conditions (Bureau of Transportation Statistics, 2017). Figure 4 illustrates how weather is still the primary cause of delays to aircraft. Despite many advances in on-board aircraft wind warning systems and ground based warning systems, wind shear is a formidable force that, coupled with a microburst can, overpower any aircraft (Albright, 2015). 


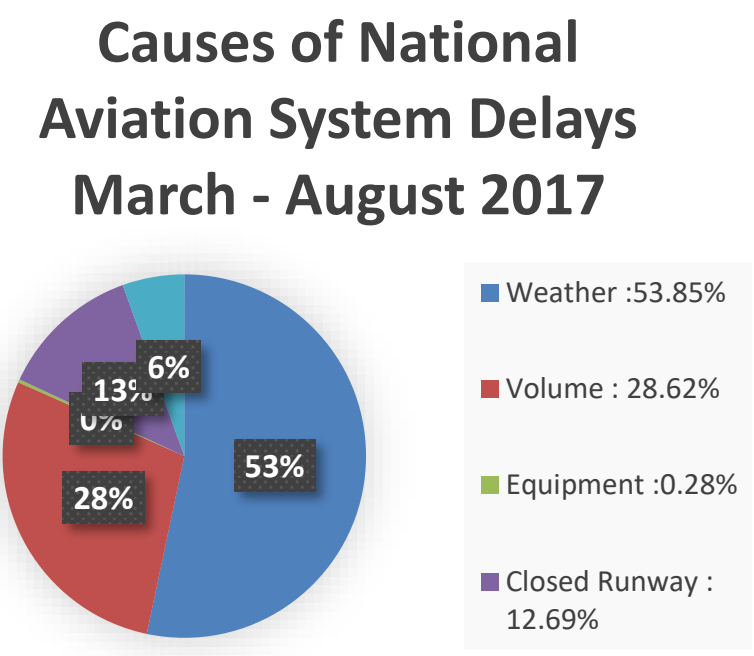

Figure 4. Percentage of NAS Delays (EUROCONTRL, 2013).

\section{II-FLIGHT GO AROUNDS AS A RESULT OF WIND SHEAR}

A flight go-around is an aborted landing on final approach of an aircraft. A go-around procedure is performed by the pilot if it is believed that the correct conditions are not suitable to make a safe landing. In a report by the International Air Transport Association (IATA) for the Go-Around Safety Forum (Kroepl, 2013), it was found that out of 1050 random data samples of Aircraft Safety Reports (ASR) on go-arounds, over 39\% listed environmental conditions as the reason for a go-around. Of these reports, $42 \%$ noted wind as the reason for a go-around. Figure 5 illustrates how the environmental conditions break down to the number of goaround manoeuvres. 


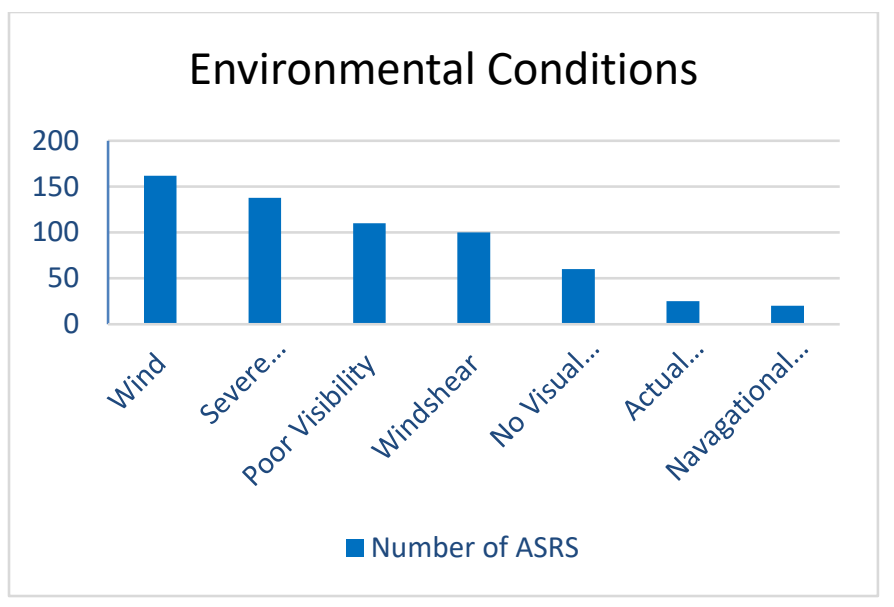

Figure 5. Environmental conditions (Kroepl, 2013).

It can be seen from Fig 6 that wind and wind shear combined represent the overwhelming majority of go-arounds due to environmental conditions. The components of wind conditions can be further analysed as shown in Fig 6 to show the number of Aviation Safety Reports for goarounds attributed to each documented wind condition. In the survey conducted by the IATA, it was found that over $78 \%$ of all go-arounds were initiated by the flight crew and $22 \%$ were initiated by the Air Traffic Control (ATC). This would seem to indicate the wind shear and turbulence data recorded by the ATC was not accurate or up to date for the approaching aircraft and it was the flight crew who deemed it necessary to abort the landing based on the conditions that they encountered on approach.

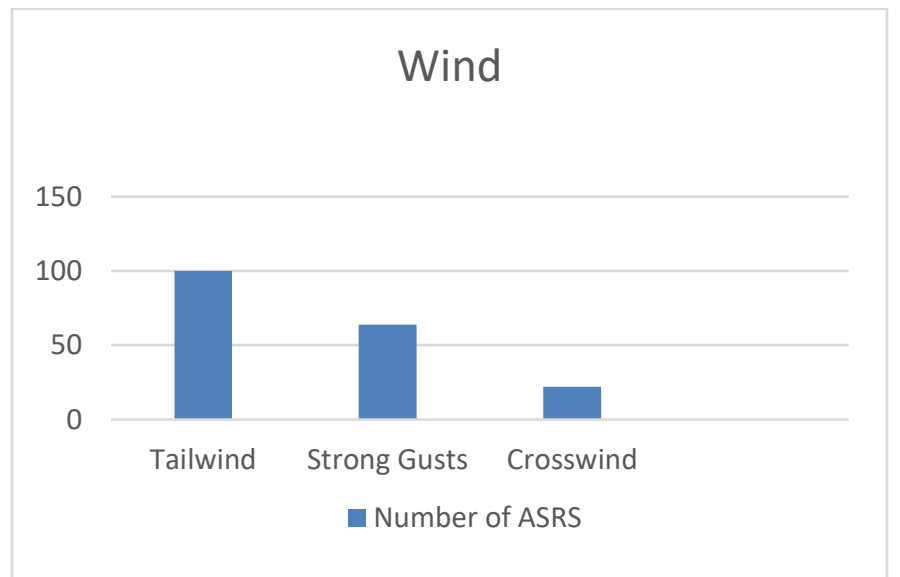

Fig 6. Environmental Wind Conditions (Kroepl, 2013). 
Fig 7 illustrates the flight crew recorded statistics from the ASRs as to the reason for initiating a go-around.

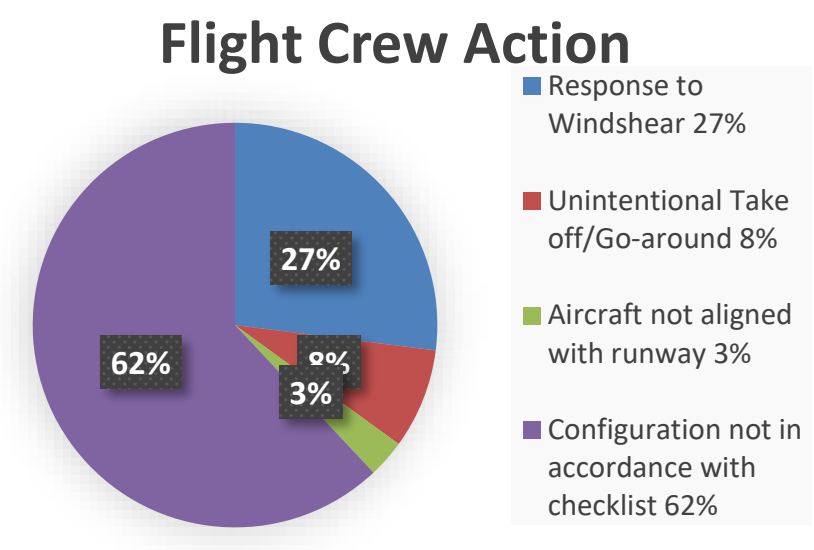

Figure 7. Flight Crew Go Around Action (EUROCONTROL, 2013).

In the data set analysed for the Go-Around Forum Report, it was noted that over $9 \%$ of the go-arounds recorded a potential hazardous outcome and on 30 goarounds that the aircraft exceeded its performance limits.

The majority of accidents in the past 10 years have occurred during this goaround procedure (EUROCONTROL, 2013). The Federal Aviation Administration (FAA) with the Boeing Company has produced documents and training videos for pilots in how best to prepare and cope with adverse wind shear conditions (FAA, 2008). The FAA and the ICAO recommendations to flight crew regarding wind shear is that avoidance is the best precaution (FAA, 1990). They further state that taking precautions and coupled with the best recovery piloting skills cannot guarantee a successful escape from microburst wind shear (ICAO, 2005). In 2011 over $68 \%$ of commercial aviation accidents were attributed to this procedure. One of the finding of the conference on Go-Around Safety Forum was that due to rapid changing weather conditions, the pilot doesn't always have the latest information on which to base a landing/go-around decision. The forum also recommended that more relevant quicker updated and improved information should be provided to flight crews on wind shear, tailwinds and wind variation on approach to landing. In the IATA report to the Go-around forum they concluded that the actual wind conditions versus the recorded and reported wind conditions given to the flight crew on final approach were an area of concern. They most worryingly noted that $31 \%$ of all aircraft exceeded aircraft performance limits during the go-around manoeuvre. 


\section{AIRCRAFT ACCIDENTS ATTRIBUTED TO LOW LEVEL WIND SHEAR}

Accidents attributed to wind shear and turbulence have reduced over the past twenty years. This can be attributed to improved equipment, such as Low Level Wind shear Alert Systems, Terminal Doppler Weather Radar and Doppler Lidar as well as better education and better awareness of the hazardous outcomes that have resulted from past air accidents. The aviation industry has published several reports on wind shear and turbulence. Air crew training now incorporates, training specific to wind shear related events such as go-around maneuvers. Air traffic controllers, pilots, airline bodies and aircraft manufacturers have all contributed to forums in which guidelines (Civil Aviation Authority, 2013) and safety rules have been stipulated in relation to wind shear and turbulence events (EUROCONTROL, 2013). Despite all of the improvements in training, equipment and aircraft over the past number of years, wind shear and low level turbulence still presents a significant risk to aircraft on take-off and approach to landing. The present advice given to pilots and aircrew is to avoid and delay take-off when a wind shear alert has been issued (ICAO, 2005). It can be seen from Fig 8 that almost 50\% of all recorded commercial accidents since 1990 were as a result of wind shear or severe low level wind gusts.

\section{Commercial Airline} Accidents and Serious Incidents 1990 - 2017

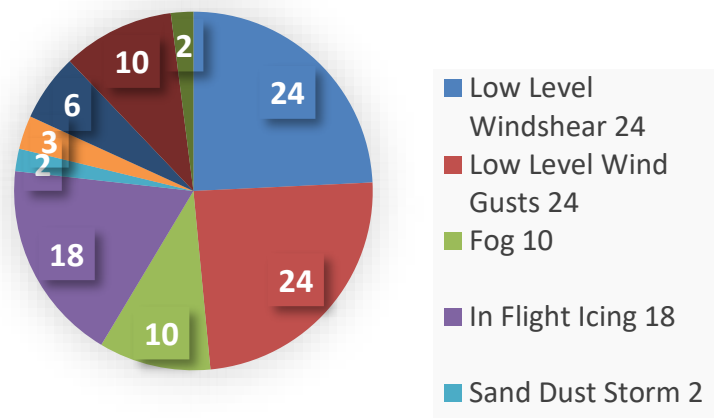

Fig 8: Environmental Wind Conditions (ATSB, 2009).

Research has found that accidents and incidents 1994 to 2016 involving commercial airlines as a result of wind shear which resulted in fatalities were as a result of a Go Around initiated by a Wind shear warning. In two incidents involving 
Qantas Airline aircraft (Australian Transport Safety Bureau, 2002), it was concluded by aviation investigation that the Air Traffic Control failed to communicate accurate up to date wind shear information to the air crews (Australian Transport Safety Bureau, 2009).

\section{COST TO AVIATION INDUSTRY FROM GO AROUNDS}

A go-around procedure has a cost implication to the airline, passengers and airport. However, it should be noted that whatever the cost of a go-around in financial terms, it is insignificant compared to the failure of a pilot to initiate a goaround which results in loss of life, loss of an aircraft and closure of an airport due to a crash.

There are many factors that can be included to determine the total cost of a go-around, which include airport operational costs consisting of gate delays, baggage fees, knock on cost for other aircraft and passengers. This study will analyze the direct cost of a go-around and include factors such as, fuel, CO2 emission charges, crew costs and aircraft maintenance. Go-arounds normally take between 10 to 15 minutes to complete (Australian Transport Safety Bureau, 2002). These figures are from the Australian Civil Aviation Safety Authority which has records an average of 800 go-arounds in a typical year making it one of the highest in the world. A go-around time of 15 minutes for has been selected for calculation purposes.

Table 1 illustrates the researched calculated direct cost for a Go Around procedure for an Airbus A320 and a Boeing 737.

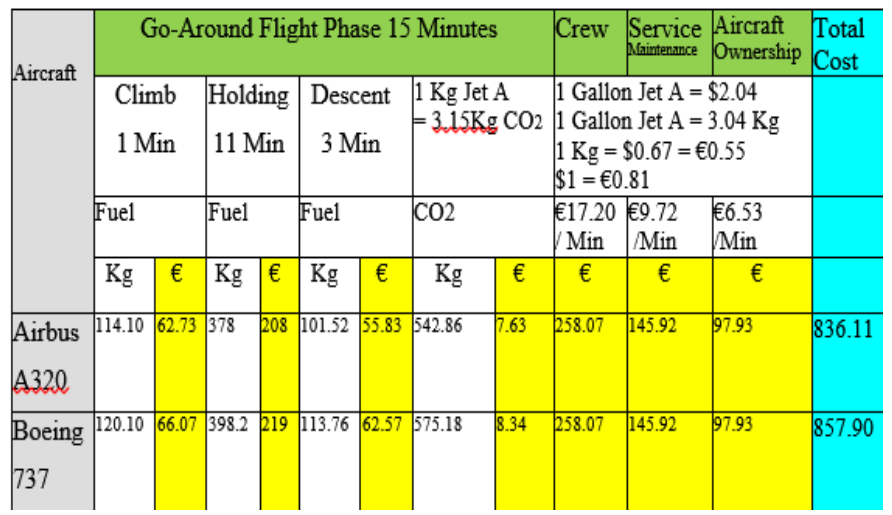

Table 1: Direct Go Around Costs (Airbus, 2018; Boeing, 2018).

'The aircraft engine type details for the Airbus A320 was obtained from the manufacturer's specifications (Airbus, 2018). The engine type for the Boeing 737- 
800 was obtained from the manufacturer's technical specifications (Boeing, 2018). The Fuel data burn figures for each stage of the go-around phase has been obtained from the ICAO engine exhaust emissions data bank (ICAO, 2018) for the exact engine type used on each aircraft in Table 5.1. The CO2 European emission allowance has been calculated at $€ 14.05 \mathrm{t} / \mathrm{CO} 2$ as at the time of research (Business Insider, 2018). The figures calculated in Table 5.2 have been computed using the latest data available for fuel, $\mathrm{CO} 2$ emissions, engine fuel and emissions data from the relevant aviation sectors, authorities and aircraft manufacturers at the time of conducting this research. The Go-around calculations have only taken into account the direct cost for this procedure. Other costs such as airport costs for baggage, gate costs, passenger costs and other associated costs have not been factored into to the calculations, due to the unobtainability of certain data from airport authorities. Table 2 is a comparison of the calculated direct cost go-around figures of this research with figures supplied by personnel in the FAA and Air New Zealand.

\begin{tabular}{|l|l|l|l|l|l|}
\hline Aircraft & $\begin{array}{l}\text { Thesis } \\
\text { Figures }\end{array}$ & $\begin{array}{l}\text { FAA } \\
\text { Figures }\end{array}$ & $\begin{array}{l}\text { Air NZ } \\
\text { Figures }\end{array}$ & $\begin{array}{l}\text { Airlines for } \\
\text { America }\end{array}$ & $\begin{array}{l}\text { Average } \\
\text { Figures }\end{array}$ \\
\hline Airbus A322 & $€ 836.11$ & N/A & $€ 878.43$ & $€ 759.98$ & $€ 824.84$ \\
\hline Boeing 737 & $€ 857.90$ & $€ 1065.69$ & N/A & $€ 759.98$ & $€ 894.52$ \\
\hline
\end{tabular}

Table 2: Comparison of Go Around Figures

It can be seen from Table 5.3 that a conservative figure of $€ 800$ could be taken for the purpose of calculating the total costs of go-arounds for a short to medium haul aircraft as shown. Despite exhaustive inquiries, it has been very difficult to obtain information to calculate exact figures for the Super heavy Airbus A380. However, using the engine details for the Engine Alliance GP7272 from the ICAO data bank and taking into account the four engines, additional crew numbers, additional maintenance and ownership costs. A figure for a 15-minute go-around would be $€ 2933$ based on the same criteria used in table 1 .

\section{WIND URCHIN AS A PROPOSED SOLUTION}

The Wind Urchin was developed to estimate accurately the precise wind yield that would be available for the location and sighting of wind turbines. Research carried out by DIT identified that miscalculation of wind as a resource had resulted in lower than expected electrical energy output from wind farms resulting in investor caution for this sector. The Wind Urchin with its increased sampling and 3D measuring capability could provide greater accuracy when 
assessing the viability of a potential site for the construction of wind farms leading to increased investor confidence in site survey predicted figures for energy output. The Wind Urchin is a multidirectional anemometer which measures wind in 3D using 64 Pitot tubes mounted and spaced equally around the surface of a sphere shaped hardened plastic molded design. The Wind Urchin can sample at frequencies up to $3,000 \mathrm{~Hz}$ providing three-dimensional data on wind speed and direction. This unique design gives the Wind Urchin the ability to measure wind shear, wind veer and low level turbulence. The Wind Urchin can output in digital or analogue format enabling the device to be integrated into a LLWAS at airport runways. It has been shown and discussed in previous chapters that despite advances in LLWAS technology, there continue to be air accidents as a result of low level wind shear during the take-off and landing stages of flights. The integration of the Wind Urchin into a LLWAS could give greater accuracy of wind speed, direction and the presence of low level wind shear. The 3D capability of the Wind Urchin can measure and illustrate wind data in three dimensions. Because of the increased sampling rate of the Wind Urchin, wind data can be recorded at a frequency of $100 \mathrm{~Hz}$ producing 64,000 data points per second producing a greater number of samples than any other anemometer currently used in aviation for a specific timeframe. The device has a wide measuring range to measure wind speed from $0-250 \mathrm{~m} / \mathrm{sec}$. The device is made from a durable hardened plastic material, there are no moving parts ensuring that this is a low maintenance device, low cost durable instrument suitable for all environments and weather conditions. See Figure 9 .

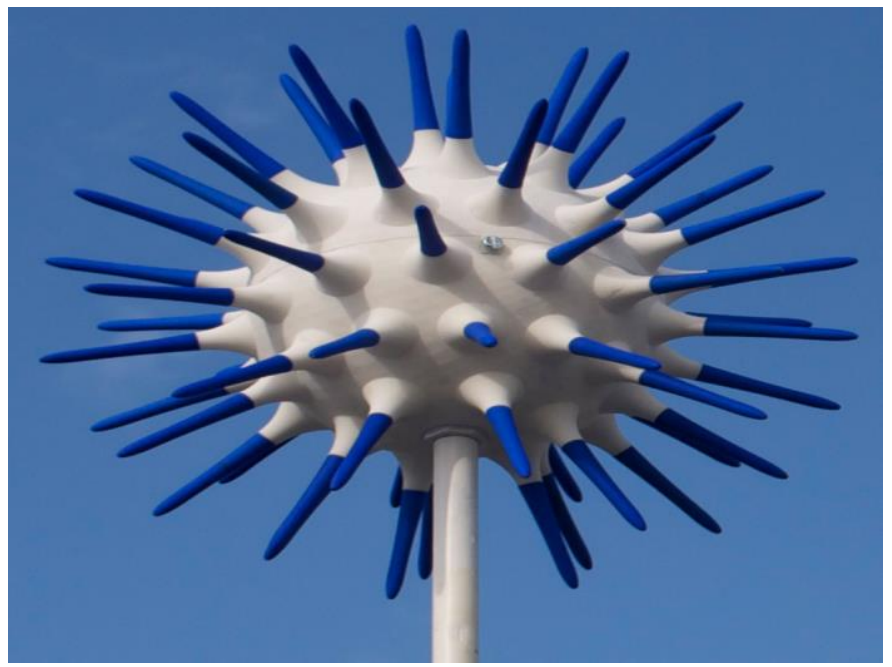

Figure 9 illustrates the Wind Urchin (Energy Resource Group, 2017). 


\section{CONCLUSION}

In Australia the Civil Aviation Safety Authority states that over 800 standard go-arounds are performed in a typical year (Civil Aviation Safety Authority, 2018). In 2017 there were 94,169 inbound international flights to Australia ( Department of Infrastructure, Regional Development and Cities of Australia, 2018).The Super Heavy Airbus A380 made up 7300 of these flights. This represents $7.75 \%$ of the total number of inbound flights. Base on the CASA figures of 800 go-arounds in a typical year, $7.75 \%$ would amount to 62 flights. Based on the figures calculated for the Medium haul flights and the A380, a conservative estimate cost for the 800 go-arounds each year in Australia would be $€ 753,336$ or $\$ 1.2$ million Australian dollars. Given the increasing volume of airline passengers to Australia it is logical to assume that the number of goarounds will increase unless there is better detection and forecasting of wind related events around the terminal and runway areas. The 800 Go-around flights in Australia represent $0.84 \%$ of the total incoming flights annually. There are between 102,500 (ATAG, 2017) and 106,500 flights (Statisca, 2018) every day taking off and landing around the world, if we took a very conservative figure of $0.01 \%$ of these flights performing a Go-around, this would cost the aviation industry $\$ 586$ million in direct costs every year based on the criteria used for the Australian model. Incorporating a system that could prevent a substantial number of Go-arounds would not only provide massive savings to airlines but increase safety to passengers and increase airport throughput and efficiency for airports, airlines and passengers. The figures calculated only take into account the aircraft direct costs, if indirect costs for airports, airlines and passengers were to be factored into the total cost of go-around related delays, the figures would be significantly higher. Incorporating a low maintenance, low cost Wind Urchin into an existing LLWAS could potentially save millions annually in direct costs alone.

\section{ACKNOWLEDGMENT}

The research reported in this paper is supported by Dublin Institute of Technology and the Energy Resource Group. The wind velocity data provided for the study was provided by the Energy Research Group and Dr Derek Kearney. The Author would like to thank the researchers in the ERG for their support and in particular Dr Derek Kearney for assisting with this paper. 


\section{REFERENCES}

Department of Infrastructure, Regional Development and Cities of Australia. (2018, June). International airlines operated flights and seats. Retrieved Apr 2018, from https://bitre.gov.au/publications/ ongoing/international_airlinesoperated_flights_seats.aspx

Airbus. (2018, March 27). Airbus A320neo. Retrieved from http://www.airbus.com/ aircraft/passenger-aircraft/a320-family/a320neo.html\#details

Albright, J. (2015, August 1). Wind shear: Has it been tamed? Retrieved October 10, 2017, from http://aviationweek.com/bca/wind-shear-has-it-been-tamed

ATAG. (2017). Facts \& figures. Retrieved Sep 2017, from https://www.atag.org/factsfigures.html

Australian Transport Safety Bureau. (2002, January 23). Aviation safety investigations \& reports: Investigation report 200100213. Retrieved from https://www.atsb.gov.au/publications/ investigation_reports/2001/ aair/aair200100213/

Australian Transport Safety Bureau. (2009, Dec 18). Aviation safety investigations \& reports :Microburst event - Sydney Airport, NSW, 15 April 2007, VH-OJR Boeing Company 747-438. Retrieved from https://www.atsb.gov.au/publications/ investigation_reports/2007/aair/ao-2007-001/

Boeing. (2018, March 27). Boeing Next-Generation 737. Retrieved from http://www.boeing.com/ commercial/737ng/

Bureau of Transportation Statistics. (2017, November 6). Airline on-time statistics and delay causes. Retrieved November 6, 2017, from https://www.transtats.bts.gov/ OT_Delay/ ot_delaycause1.asp?type $=5 \& \mathrm{pn}=1$

Business Insider. (2018, March 29). CO2 European emission allowances. Retrieved from http://markets.businessinsider.com/commodities/co2-emissionsrechte

Civil Aviation Authority. (2013, June 4). Missed approaches in response to onboard windshear alearts. Retrieved October 5, 2017, from https://skybrary.aero/bookshelf/books/2303.pdf

Civil Aviation Authority. (2018, January 23). Go-arounds. Retrieved from https://www.casa.gov.au/ standard-page/go-arounds

Civil Aviation Safety Authority of Australia. (2018, Jan 2). Go-arounds. Retrieved Apr 2018, from https://www.casa.gov.au/standard-page/go-arounds

Energy Resource Group. (2017, Apr). WindUrchin. Retrieved from http://www.energyresourcegroup.io/windurchin

EUROCONTROL. (2013, June 18). Go-around safety forum. Retrieved Jan 21, 2017, from https://www.skybrary.aero/index.php/Portal:Go-Around_Safety_ Forum_Presentations 
Federal Aviation Administration. (1990). Pilot wind shear guide. Retrieved March 2018, from https://www.faa.gov/documentLibrary/media/Advisory_Circular/AC0054.pdf

Federal Aviation Administration. (2008). Wind shear. Retrieved Mar 2017, from https://www.faasafety.gov/files/gslac/library/documents/2011/Aug/56407/FAA\% 20P-8740-40\%20WindShear\%5Bhi-res\%5D\%20branded.pdf

Flight Safety Foundation. (2009). Flight safety foundation alar briefing note 5.4 wind shear. Retrieved October 10, 2017, from https://www.skybrary.aero/bookshelf/ books/812.pdf

International Civil Aviation Organization. (2005, November 17). Manual on low-level wind shear. Retrieved from https://skybrary.aero/bookshelf/books/2194.pdf

International Civil Aviation Organization. (2018, March 27). ICAO aircraft engine emissions databank. Retrieved https://www.easa.europa.eu/easa-andyou/environment/icao-aircraft-engine-emissions-databank

Kroepl, M. (2013, June). Go-arounds. Retrieved from https://www.skybrary.aero/ bookshelf/ books/2307.pdf

Statisca. (2018, Oct). Global air traffic - number of flights 2004-2018. Retrieved from https://www.statista.com/statistics/564769/airline-industry-number-of-flights/ 